\title{
Committing Sociology: Being Healthy, Happy, and Up-High in St. James Town
}

\author{
LAURA BISAILLON, PhD, Interdisciplinary Centre for Health and Society, Social \\ Justice Education, University of Toronto ${ }^{a}$ \\ MEHDIA HASSAN, BSc, Social Justice, Lakehead University ${ }^{\mathrm{b}}$ \\ MARYAM HASSAN, BA, Sociology Department, University of Toronto ${ }^{c}$
}

\begin{abstract}
There is a doggedly persistent, pervasive, and pernicious tendency to individualize rather than socialize problems. This is a discernable pattern that we see all around us, independent of any one particular social context. This collaboratively produced article is an example of and commitment to feminist praxis. We intentionally mobilize the "tools of social science, friendship, and the power of conversation" (Mountz, 2016) to bring to life ideas that Mehdia experienced for the first time in Laura's undergraduate classroom. Specifically, she and fellow classmates, along with Maryam, learned how to cultivate and employ their "sociological imagination" (Mills, 1959, 2000); connecting aspects of biography with materially arising social conditions. The aim of such inquiry is to generate new insights and critically minded, contextually situated, and empirically supported explications for how things happen for and around us in the world we inhabit. In doing so, we are able to "sociologically reimagine" analysis by using visual modes of inquiry and intentional "interdisciplinary entanglement" to blur the boundaries between traditional and so-called non-traditional modes of knowledge making (Jungnickel \& Hjorth, 2014). We argue that the time is absolutely upon us to "commit sociology,"[1] and we offer this article as an intervention that does just this.

\section{[1] As per https://www.youtube.com/watch?v=9yT9dhHsKwc}

Keywords: Care; feminist praxis; politics of health and illness; sociological imagination; visual sociology

\footnotetext{
${ }^{a}$ Laura Bisaillon, Ph.D., is assistant professor at the Interdisciplinary Centre for Health and Society and Social Justice Education Department. In a prior career, she worked as a community and social services worker in Canada the Horn of Africa. She is troubled by how socially arising inequities press bluntly on people experiencing marginality. Through her research agenda, she ethnographically explores the politics of knowledge production. She strives to generate scholarship that can be used to correct and resist by
} 
producing alternative and transformative forms of knowledge. Her website is:

http://www.utsc.utoronto.ca/healthstudies/laura-bisaillon

Contact: Laura Bisaillon, $\mathrm{PhD}$, Interdisciplinary Centre for Health and Society, Social Justice Education, University of Toronto, 1265 Military Trail, Toronto, Ontario, Canada, M1C 1A4,

lbisaillon@utsc.utoronto.ca

${ }^{b}$ Mehdia Hassan, B.Sc., is pursuing a master's of arts in Social Justice at Lakehead University in Thunder Bay. She graduated from the University of Toronto with a bachelor's of science in health studies and psychology. She uses creative methods, such as visual arts, to explore, understand and express inequities. Her broader aim is to contribute in advancing social change for people who experience marginality. Read her latest publication: http://home.blnkpage.org/health-science/the-corner-that-cares/

Contact: Mehdia Hassan, BSc, Social Justice, Lakehead University, 955 Oliver Road, Thunder Bay, Ontario, Canada, P7B 5E1, mhassan6@lakeheadu.ca

${ }^{c}$ Maryam Hassan, BA, recently completed her undergraduate degree at the University of Toronto, majoring in Sociology, and minoring in Visual Studies and Near and Middle Eastern Civilizations' Studies. She uses creative methods such as photography, painting, and installation art to bring awareness to social inequities. Her mixed media installation Roshan, which is about social injustice in Afghanistan, was displayed at several exhibitions. For this piece, she was awarded first prize in the 2017 Student Art Exhibition at the University of Toronto Art Museum. See her piece:

http://www.arts.utoronto.ca/SPSAEAwards/SPSAE_2017.htm

Contact: Maryam Hassan, Sociology Department, University of Toronto, 73 Queen's Park Crescent, Toronto, Ontario, Canada, M5S 1K7, maryamhassan@hotmail.ca 
There is a doggedly persistent, pervasive, and pernicious tendency to individualize rather than socialize problems. This is a discernable pattern that we see all around us, independent of any one particular social context. This is inconsistent with longstanding findings and research evidence on the social determinants of health, for one thing (Bryant, 2016; Raphael, 2016). We are currently witnessing a rise in intolerance and a veer to the social and political right around the world. Our collective historical past reveals the harms associated with trends of this sort. Students are thirsty to know how to make sense of what they read about and experience, they look to elders, including university professors they trust, for social guidance and scholarly direction. Since individualizing and extremism are human practices, they are contingent and changeable. We argue that the time is absolutely upon us to "commit sociology,"1 and we offer this article as an intervention that does just this.

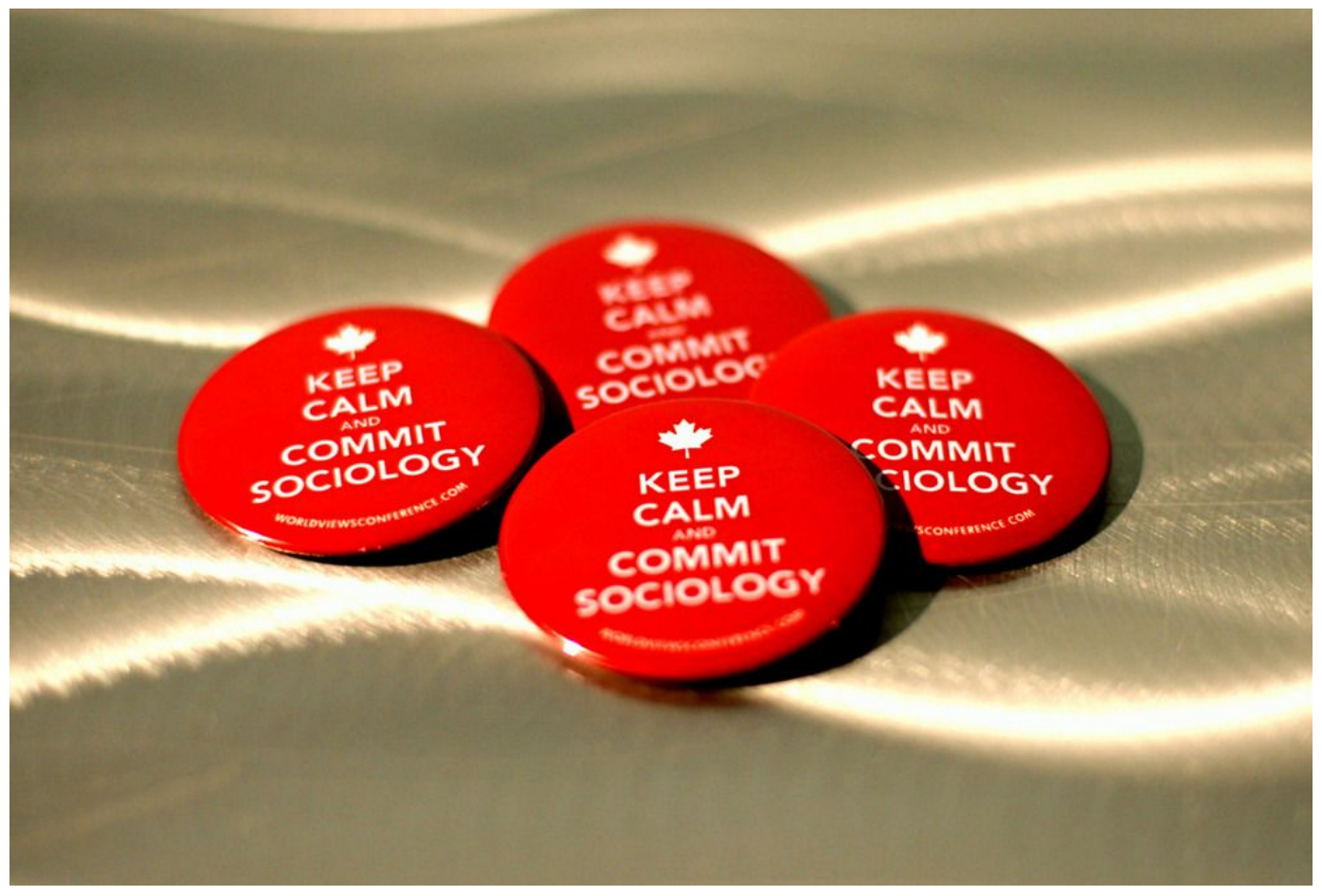

Fig 1 - Photograph of a grouping of red coloured lapel buttons bearing the bold statement, written in white, "Keep calm and commit sociology."

${ }^{1}$ See https://www.youtube.com/watch?v=9yT9dhHsKwc 
This is a collaboratively produced article that is an example of and commitment to feminist praxis. We matured and produced what appears below over approximately one year of iterative sharing, and our voices each are present in the dialogical narrative. We intentionally mobilized the "tools of social science, friendship, and the power of conversation" (Mountz, 2016) to bring to life ideas that Mehdia experienced for the first time in Laura's undergraduate classroom. Specifically, she and fellow classmates, along with Maryam, learned how to cultivate and employ their "sociological imagination" (Mills, 1959, 2000) to connect aspects of biography with materially arising social conditions. The aim of such inquiry is to generate new insights and critically minded, contextually situated, and empirically supported explications for how things happen for and around us in the world we inhabit. In doing so, we are able to "sociologically reimagine" analysis by using visual modes of inquiry and intentional "interdisciplinary entanglement" to blur the boundaries between traditional and so-called non-traditional modes of knowledge making (Jungnickel \& Hjorth, 2014).

\section{Laura begins:}

When my former student, Mehdia, shared in an email after the first lecture that she lived in the St. James Town neighbourhood in Toronto's inner city core, I was happily surprised, as was she, because, as we found out, this meant that we were neighbours. As it turns out, we actually live a two-minute walk from each other on the same street. Her and her two immediate siblings, Maryam and Muneer, were born into this community. My family and I are recent immigrants to it, and we have come to feel at home here. 


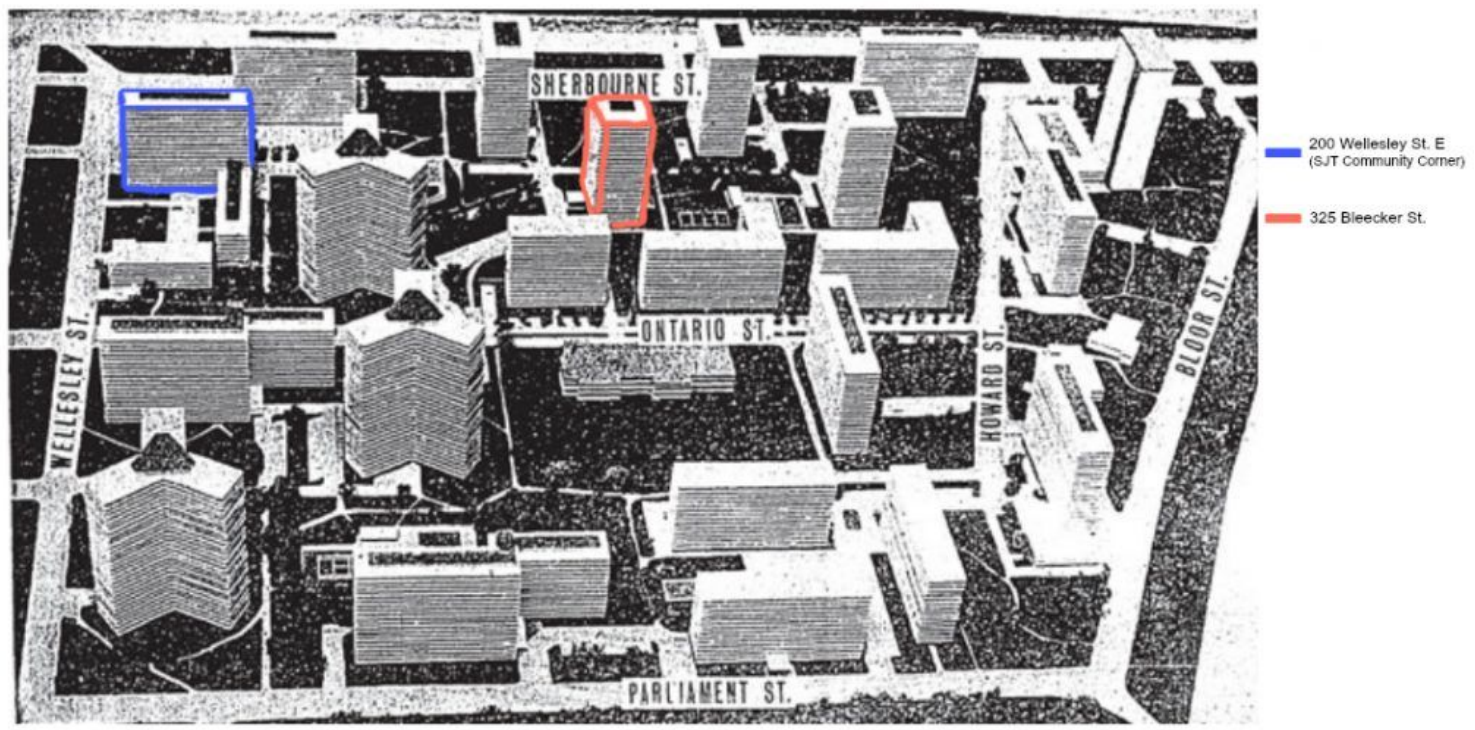

Fig 2 - An architectural drawing, in black and white, produced in aerial view, showing the high-rise apartment building community of St. James Town. This area is bounded to the east by Parliament Street; to the west by Sherbourne Street; to the oriented east looking west; north by Howard Street; and, to the east by Wellesley Street. The apartment building where Mehdia and Maryam live, at 325 Bleecker, is coloured in orange. The Community Corner office, at 200 Wellesley, is highlighted in blue.

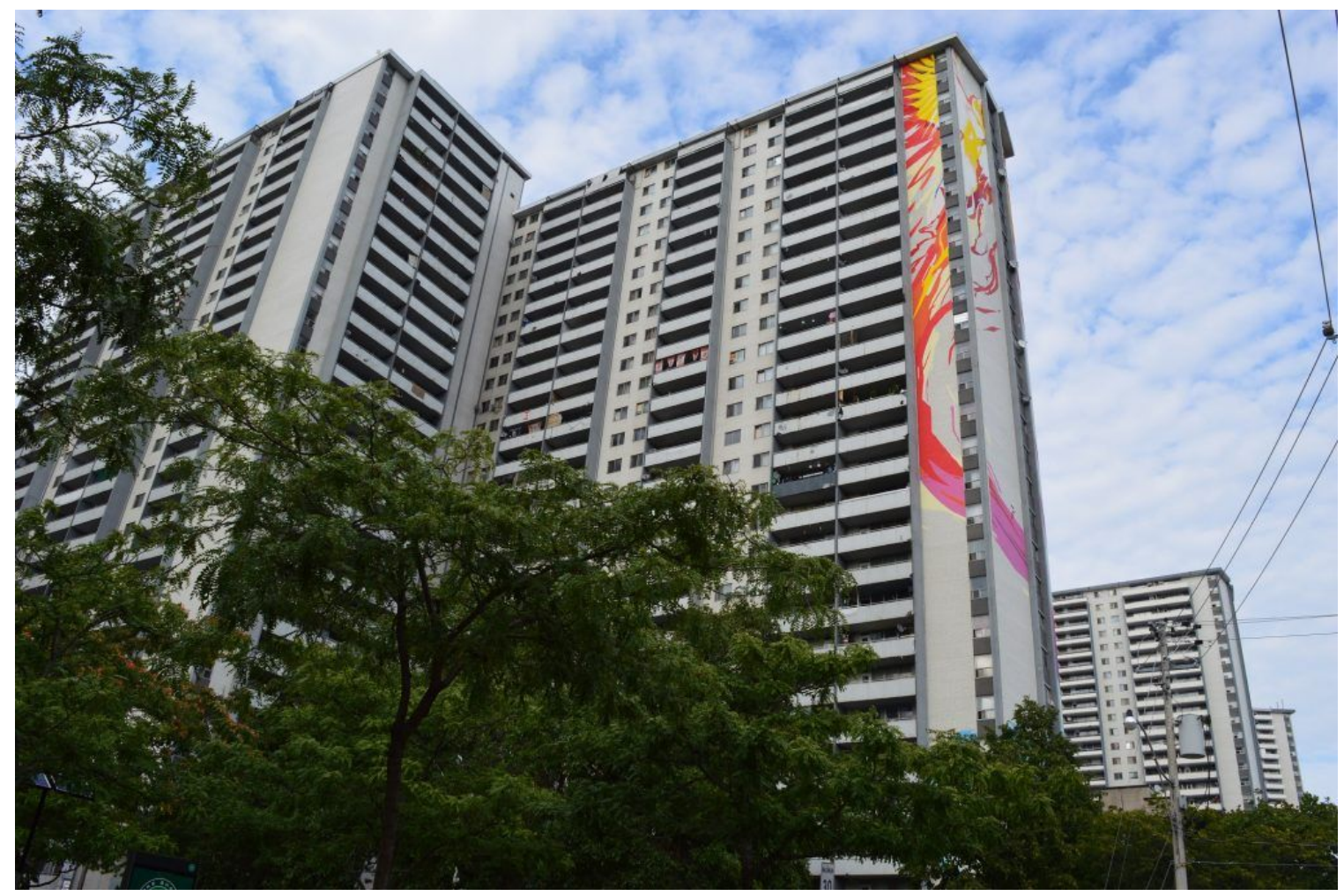

Fig 3 -Outdoor photograph featuring the high-rise apartment tower at 200 Wellesley. In the background, heading east, two other towers are visible. The angle is from ground to blue summer sky. We see leafy treetops in the foreground. 
Mehdia was enrolled in my Social Determinants of Health course, which is a mandatory course for second-year undergraduate Health Studies' students at the University of Toronto Scarborough's newly created Interdisciplinary Centre for Health and Society. She introduced herself to me at the beginning of the second lecture. The initial email communication between us made way for later discussions in my office, and still later, in a nearby neighbourhood coffee shop. We decided to collaborate to organize an in-person class visit to explore St. James Town. The aim was to see, experience, reflect on, and talk about social shapers of health and illness from the inside out, that is to say from the standpoints of its residents who know the surroundings with intimate familiarity (El Magammar, 2016). In this class, I guide students to develop skills for doing “social autopsy" (Klinenberg, 1999), which involves them learning new-to-them ways of seeing, talking about, and analyzing the world they inhabit. I teach them to recognize the value in using creativity and criticality in equal measure (as per Finn, 2015) to begin to explore the conditions and circumstances of their lives. I lead them to conceive of and use these conditions as valuable and relevant places to begin social inquiry.

The process of using creative methods is not always neat, ordered, or linear (Jungnickel \& Hjorth 2014). Often times, the mess and entanglements that provide rich textures, artifacts, places, and emotions are hidden from professional performativity. The smoothening and fine-tuning of this mess can be reductive. When these untidy parts of research are elided, new discoveries are also unnoticed. Part of our politic, then, is the opening of our creative process so that it serves as testimony that scholarly knowledge production and dissemination are anything but intense and frenetic. Embracing the 
messiness and uncertainty of creating, not to mention the practice of patience and perseverance for the time it takes to arrive at a satisfactory final product, whether a solo or joint effort, is integral to how we actually produce valuable new knowledge.

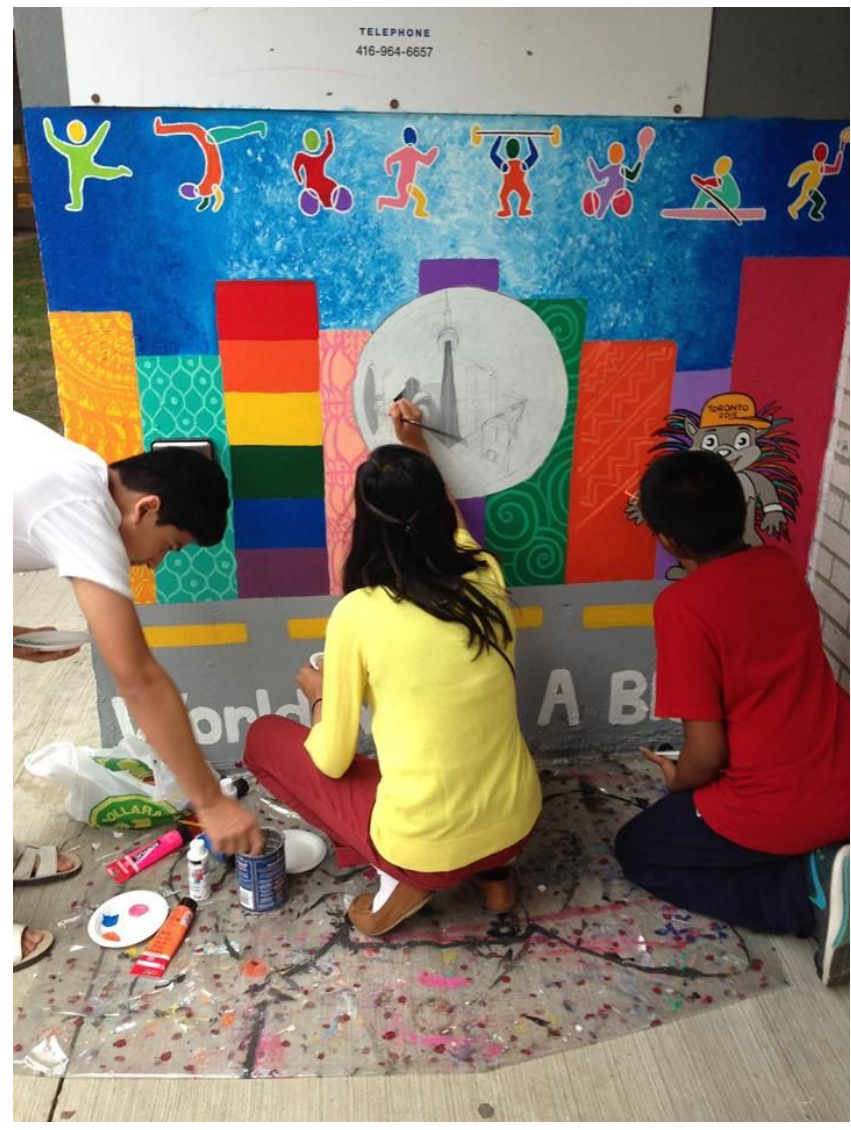

Fig 4 - Outdoor photograph in which we see three young adults crouched side-by-side, collaborating on colourful mural. The CN Tower is seen in the centre. The piece is painted onto the south-facing wall at the entrance of the Community Corner at 200 Wellesley. Members of Serendipity Visual Arts completed the mural at the occasion of the Pan Am Games, Toronto, 2015. Mehdia's back is to us, in the centre.
“Learning about Mills’ sociological imagination changed the way I think about my neighbourhood, that is, as somewhere I am pleased to call home," Mehdia wrote to me in an email. Her note both touched and elated me. Mentoring health sciences' students, and helping them to think "organizationally" and "institutionally" (Smith, 2006) is an exciting, if sizeable, challenge for me and other immediate faculty colleagues whose courses are organized within commitments to critical social science. We use this term to refer to "a broad range of work that might be considered critical, reflexive, post-positivist or otherwise conversant with developments in contemporary theory in the humanities and social sciences ... a contrast term that distinguishes a heterogeneous but 
recognizable research practice from established forms of health sciences research" (Mykhalovskiy \& Cain, 2008).

I explicitly attribute the challenge of teaching in this way to the muscularity of biomedical, positivist, and numerical forms of reasoning within health milieus. Specifically, these continue to be the dominant organizers of health science teaching and research as conventionally understood (Eakin \& Mykhalovskiy, 2005; Lock \& Nguyen, 2010). My pedagogical approach includes challenging and displacing the centrality of these relations by showing students how and in what ways that which happens to and around us is nested in broader social relations and processes. In doing this, students come to be able to extricate social problems they and others they care about experience from predominantly or exclusively individualized and individualizing interpretations. I guide them, at once firmly and empathetically (and in ways that they are initially apprehensive and unfamiliar about, in my experience), and thus away from the priorities and rationalities of positivism; leading them toward places of curiosity and discovery about "subjectivity, embodiment, and experiences [that] always affect research, whether it is recognized or not" (Taber, 2015). 


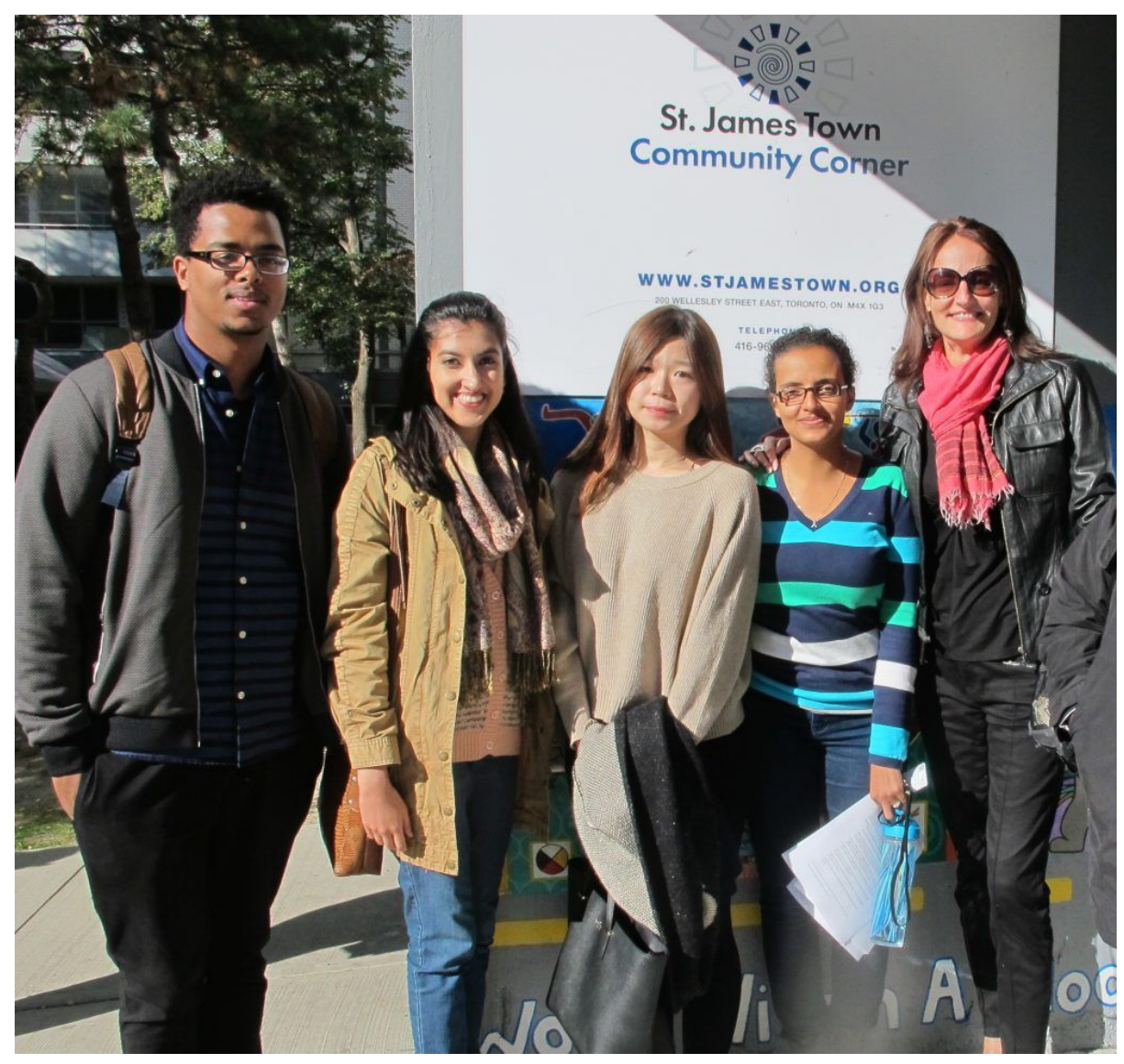

Fig 5 - Photograph taken outside mid-way through the site visit. We see five people standing closely together with their backs against the south-facing wall at the entrance of the Community Corner at 200 Wellesley. They are in front of the mural featured in Figure 4. We see Laura, at right, and Mehdia, second from left. Orit Adose, Community Corner employee, second from right, joins classmates Simon Dessie and Doris Yu.

Our photos capture scenes of everyday life in St. James Town's past and present. Images are from public and our private collections. Some of these were taken during our class site visit in October 2016, and others were taken in July 2017. Through these images, we explore and make visible the activist "caring work" that neighbourhood residents do (Mukhopadhyay, 2016). In this article, we use the term work to signify activities that any of us do that "take time, effort, and intent" (Smith, 2005). The work that we call attention to happens within understandings of solidarity among residents in a tight cluster of eighteen high-rise apartment buildings that are between fourteen and thirty-two stories tall. This labour also transpires within commitments to live well despite material signs 
and consequences of physical and social neglect. The building stock and surrounding infrastructure, constructed over a decade beginning in the late 1950s, is extremely worn and very poorly maintained (Barnes, 2011). St. James Town is administratively grouped within a wealthy, adjacent borough named Rosedale. The significance of this is that the former is subsidized differently and less plentifully than other, comparable inner city neighbourhoods in Toronto such as nearby Regent Park, for example. Importantly, according to Mehdia and Maryam, the varied and ongoing activism work that they and fellow residents do and have done through time talks back to, offsets, nuances, and corrects mainstream ideas that St. James Town is somehow or inherently a so-called or reputedly "bad neighbourhood” (El Magammar, 2016).

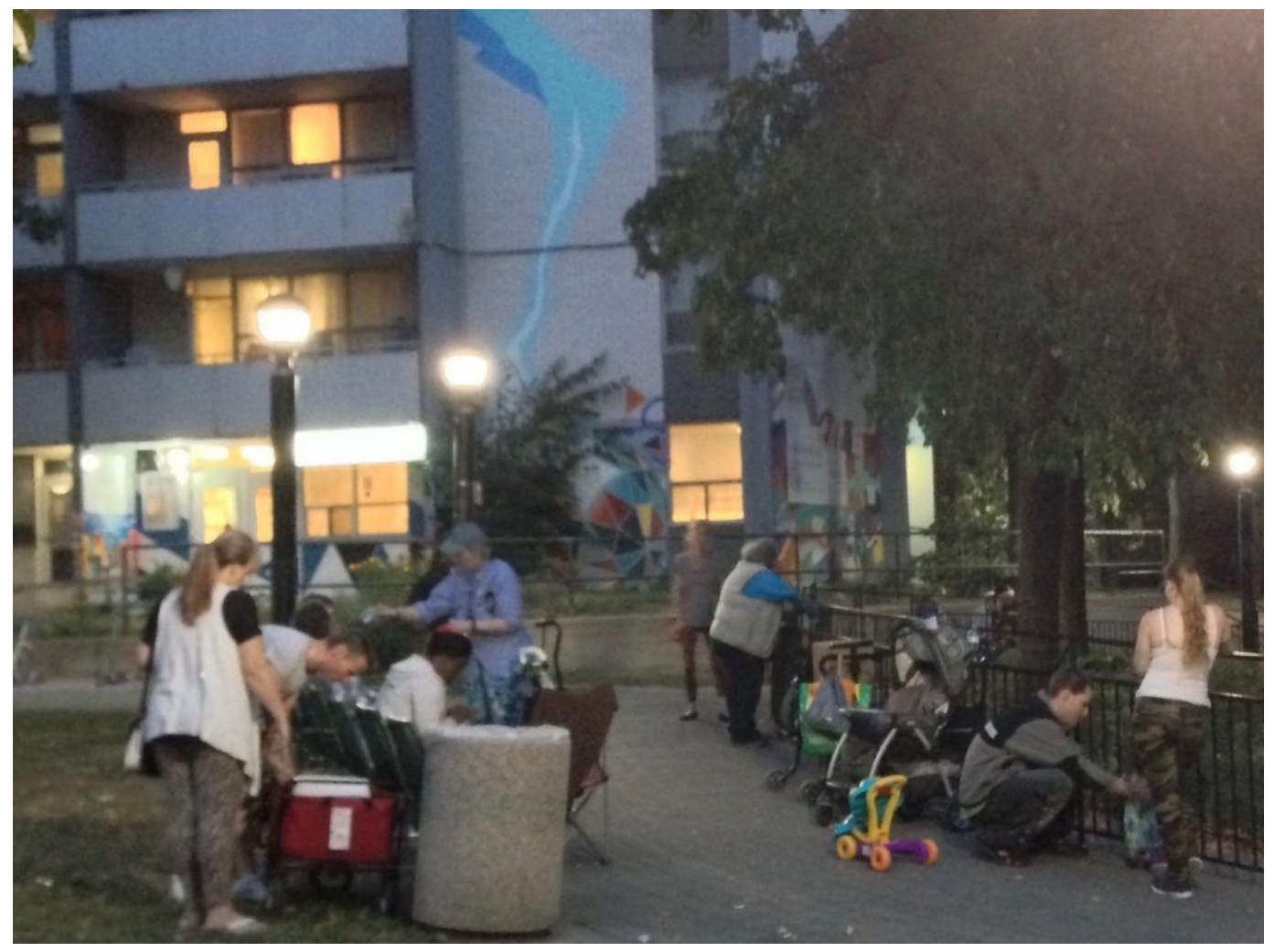

Fig 6-Photograph taken outside, at twilight, toward the end of a Toronto summer. In the foreground, we see nine adults of various ages socializing in a mini park. The Community Corner at 200 Wellesley is in the background. People are standing and seated in groups; talking and exchanging goods with each other; some are wearing hats, others have ponytails; and, some are black skinned, some are white skinned. We see strollers, shopping baskets, and walkers. 


\section{Mehdia and Maryam continue:}

We have a strong connection to my neighbourhood, St. James Town. We have always felt this way. After all, this community, which is demographically, ethnically and diverse in a sizeable host of other ways, has been our home all our lives. Staying in the same neighbourhood, moving across the street almost two decades ago, from one apartment building to another, is the only way we have relocated to date in our lives. We are grateful for the good nurturing and enriching experiences that this community has afforded us. We are writing this article in our family's apartment on the ninth floor of one of the high-rise towers that are the signature features of this neighbourhood. This community and the people living in it have taken good care of our family; the ideas of caring work that we mobilize are manifest in many gestures that might be taken-for-granted because they are habitual and part of everyday interactions with our neighbours. We have lived here for more than two decades, and we can say with certainty that neighbours have become as close as family in some cases. We have made efforts to 'be there' through our respective family's ups and downs. Interestingly, the elevators are places where caring work occurs daily. People who have watched us grow hold the door for us, and us for them, as we discuss the events of our days and the progression of our university studies. We give and receive expressions of caring about each other's health and wellbeing. Bits and pieces of conversations emerge within relations of caring, and are easy and natural because spontaneous. 


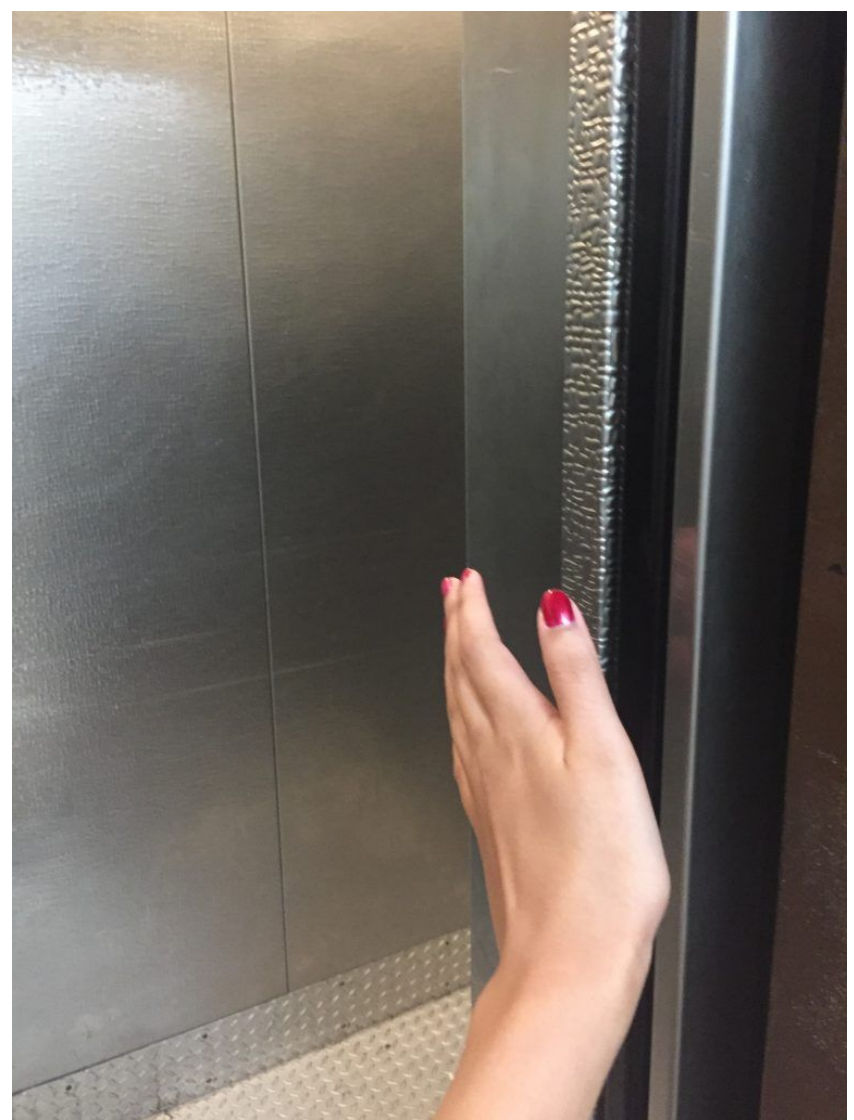

Fig 7 - Photograph taken indoors, on the ninth floor of the apartment building where Mehdia and Maryam live at 325 Bleecker. We see Mehdia's outstretched hand, fingernails painted red, holding the elevator door open, though there are no passengers. Beyond her hand, the steel coloured interior of the elevator.

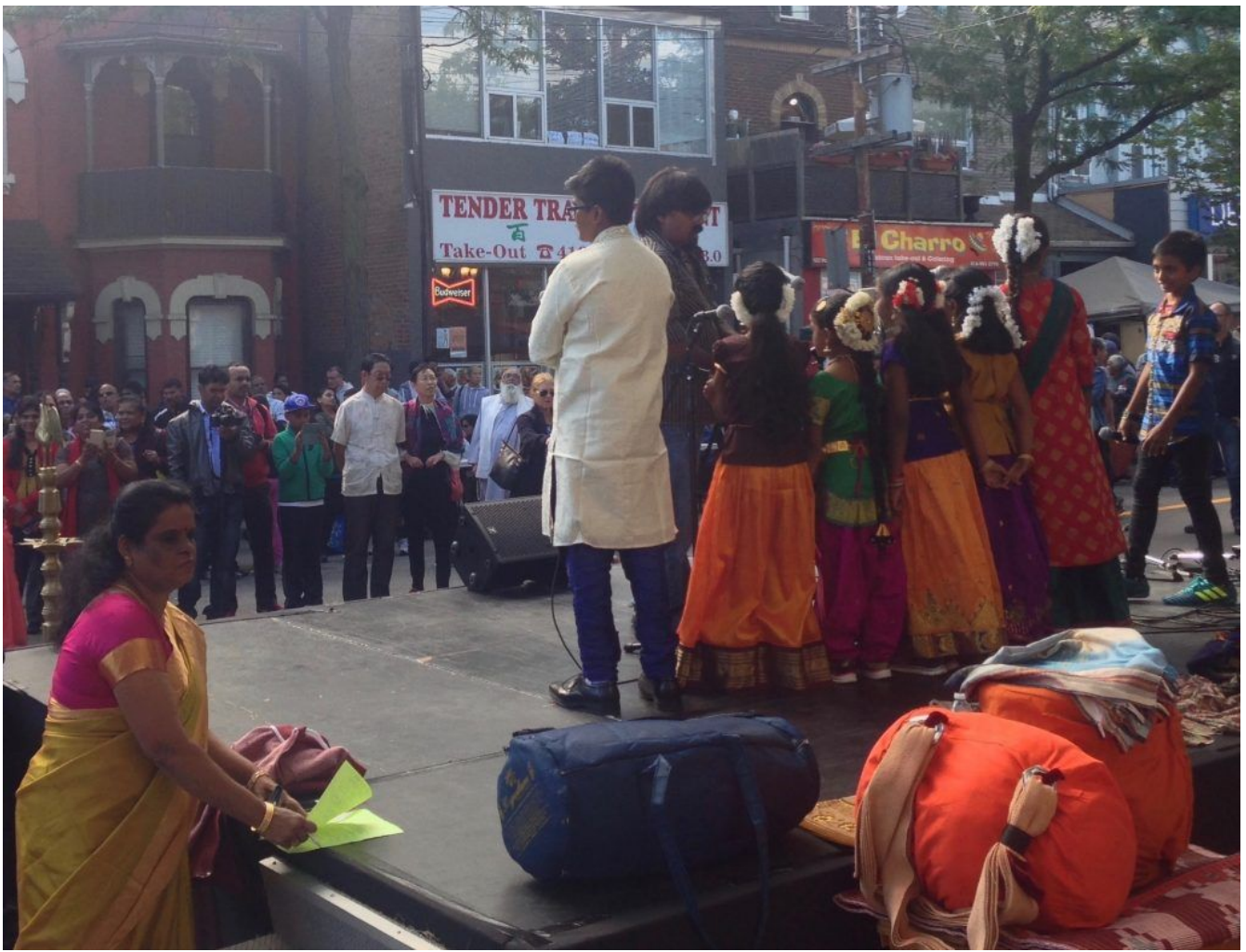

Fig 8 - Photograph taken outside, along Parliament Street, near the intersection with Wellesley, toward the end of a Toronto summer. The occasion captured is a community festival. The street is closed to traffic. We see seven 
South East Asian children dressed in their traditional clothing, backs to us, on stage, and an adult woman, in a sari, assisting, to the left of the frame. The youngsters are preparing to perform for a crowd of onlookers of all shapes, sizes, ages, and countries of origin.

Our analysis in/of/on St. James Town evoked our senses. We contemplated the sights, smells and sounds we discovered. As part of our analysis, we created three soundtracks that we include below. These audios are invitations to our readers to join in experiencing this neighbourhood.

\section{4))} Link to Soundtrack 1: "Cheerful Chorus of St. James Town Children."

As we reflect, perhaps it is reciprocity that motivates us to get involved in activist-oriented work in St. James Town. We are co-founders of Serendipity Visual Arts. During 2014, we created and conducted a visual arts workshop for youth who wanted to learn about and practice arts, but whose families could not support them because costs were too great. We received funding from ArtReach Toronto and the Toronto Arts Council to support this initiative. In 2016, the community awarded us a Grassroots Organization Award in honour of our contributions over a two-year period. Today, we are guided by and inspired to continue to work alongside and to give back to St. James Town residents. Without a doubt, the neighbourhood has formed and informed the women we have become. We see the significance that geographical specificity has on our understanding of who we are. Without a doubt, our social identities are deeply entangled with feelings of rootedness about place, home, and belonging (Spencer \& Cox, 2017).

Before taking Laura's Social Determinants of Health course, I, Mehdia, was not familiar with the sociological imagination as an approach and way to investigate the relationships between biography, structure, history, and culture. In this class, I learned how to identify, explore, discuss, and critique such relations as they shape people's living conditions in St. James Town. To that point in my undergraduate experience, I had not been socialized or 
trained to consider or understand the analytic value of subjectivity. I came to be curious about how critical health and social scientists conceive of and use bias differently than how I had been asked to consider this concept. During the semester, as I walked around my neighbourhood, I put on my newly found sociological imagination glasses, and put my privileged "insider" knowledge and position to work (Contreras, 2015). I was able to make fresh associations between people, places, issues and practices. Making these linkages has grown what I know about my home turf, and analyzing in this way has raised my consciousness about the politics that produce, organize and sustain my home community.

For the final assignment in this course, I was inspired, and Laura and Maryam encouraged me, to create an original piece of art. "Home" is a mixed media installation that shows and tells features of my life in St. James Town using my newly formed sociological imagination sensibilities. On its outside, the wooden box is ornamented with sketches and more elaborate renderings of the neighbourhood's signature high-rise apartment towers. On its inside are mounted photographs of scenes from our family life over nearly three decades. The experience of creating this piece was deeply moving. My creative process revealed buried, if not lost, memories of childhood and adolescence. I rediscovered and drew from these experiences. As I would later come to learn through graduate training, the act of creating, and the way I was moved and transformed through the opportunity to create, has been documented and analysed for how it evokes what we might call lost experiences, and indeed our memories of these (Spencer \& Cox, 2017). 


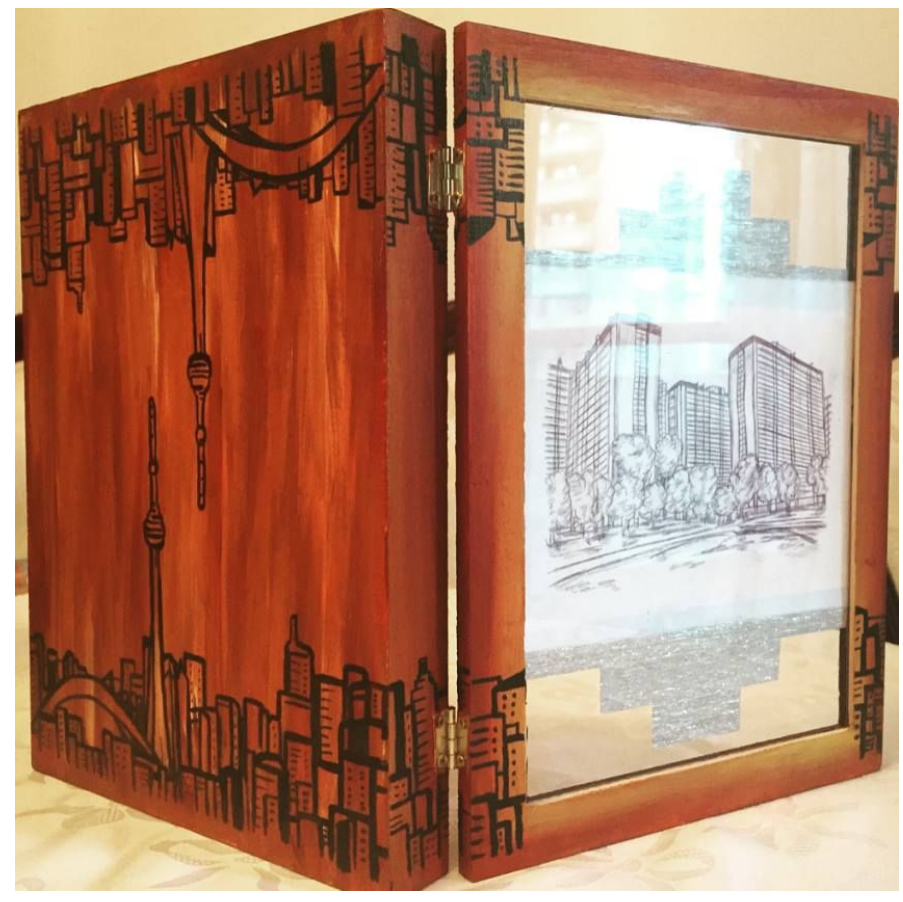

Fig 9-Photograph taken indoors featuring the back of Mehdia's piece of art entitled, "Home." This artwork is made of wood, glass, brass hinges, photos, and original drawings. On both panels, we see the artist's interpretation of the CN Tower and the St. James Town high-rise apartment community. While we do not see them, family photos adorn the reverse of both panels.
When Laura and I decided to co-organize a site visit to St. James Town, I remembering feeling thrilled! I would get the opportunity to introduce classmates to my community. Our suburban campus is far from the inner city, and for this reason, I never imagined that I would one day lead a group of peers through these streets. As mentioned above, my siblings and I have, through the years, been involved in

various arts projects and programming in St. James Town. Because of this involvement, I decided that it would be original and relevant to explore and interpret the neighbourhood through its public art, much of which is crafted by local residents. We were a small group of people, which was intimate and enjoyable. I was nostalgic while we strolled together. I explained and commented on the murals, responding to colleagues' questions. They were born in Ethiopia and China, and we discussed similarities and differences in housing stock, form, and financing between and within countries, cities and other contexts with which we were familiar. My classmates were struck by the verticality and density of the neighbourhood, which is, in fact, the densest in Canada. There are about 65, 000 versus 
890 people per square kilometre for St. James Town and Toronto, respectively. An estimated forty percent of families in our community live below the poverty line, and most people are new immigrants. After English, Tagalog and Tamil are languages most commonly spoken in people's homes (Toronto City Mission, 2017).

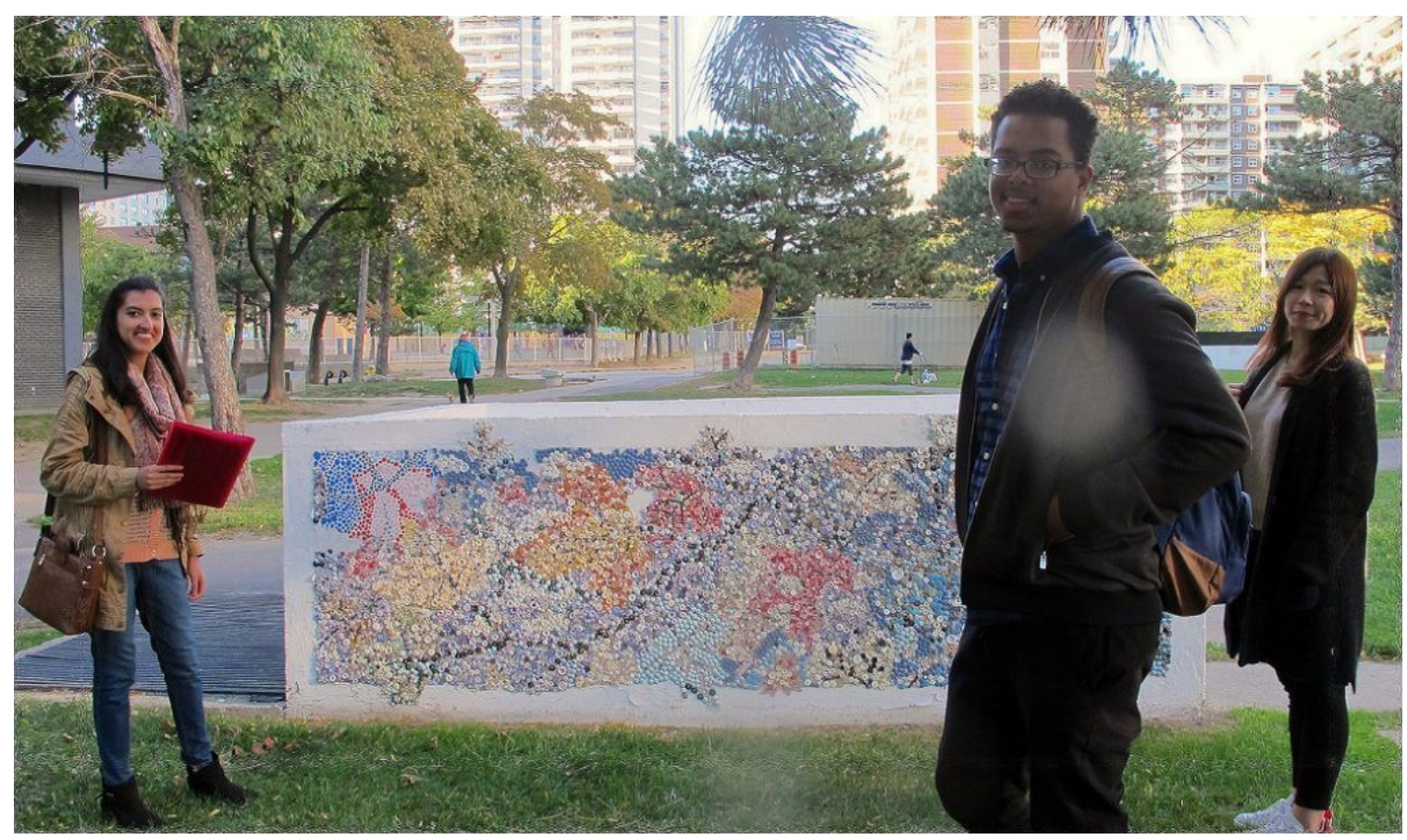

Fig 10 - Photograph taken outside in late fall near the centre of the St. James Town complex of high-rise apartments. We see Mehdia, Simon Dessie, and Doris Yu posing for Laura's photo of them during the site visit. The students are standing in front of a mural composed of colourful buttons fastened to a low-lying concrete structure. Mehdia explained that neighbourhood children created this piece.

At this writing, we are frustrated that St. James Town is under siege. What is happening here mirrors the trend in Toronto more broadly, where land developers throughout the sprawled metropolitan area are building massive numbers of massive high-rise towers (Hume, 2017a). New condominium towers in St. James Town mean more people, more density, and more associated side effects. Our ninth floor apartment looks directly onto a main building site. This site has been active, and actively producing noise and particle pollution, for more than two years. We have needed to practice considerable patience, 
given that we are disturbed for twelve hours a day from Monday to Friday starting at 7am. My mother has developed chronic sleep problems and endures headaches that have newly manifested since the noise and vibrations began. Our family is aligned in empathy and frustration with fellow residents since we are collectively and chronically disturbed. Lower levels of the building, closest to the site, are where people, many of whom are in wheel chairs, experience the most disruption to their wellbeing. In our unit, we now have little sunlight since the high-rise in front shades our building.

As a community, we have no choice but to breathe and continue to endure a lot of dust. Often, over the past year, we have looked out of our living room window and thought that the day was cloudy, only to find out, once setting foot on the pavement outside, that the day had actually dawned brilliant and sunny. The development of the newest tower immediately in front of ours - and the presence of the associated heavy machinery that has been parked around the clock every day of the week for over two years-is a common topic of discussion among residents who explore the ways in which they are affected. We wonder whether the persistent hammering and drilling noises will ever cease. The sum of these experiences is a compelling and disturbing example of how human health and wellbeing are affected by the social conditions in which we are immersed, and over which we have little to control. 


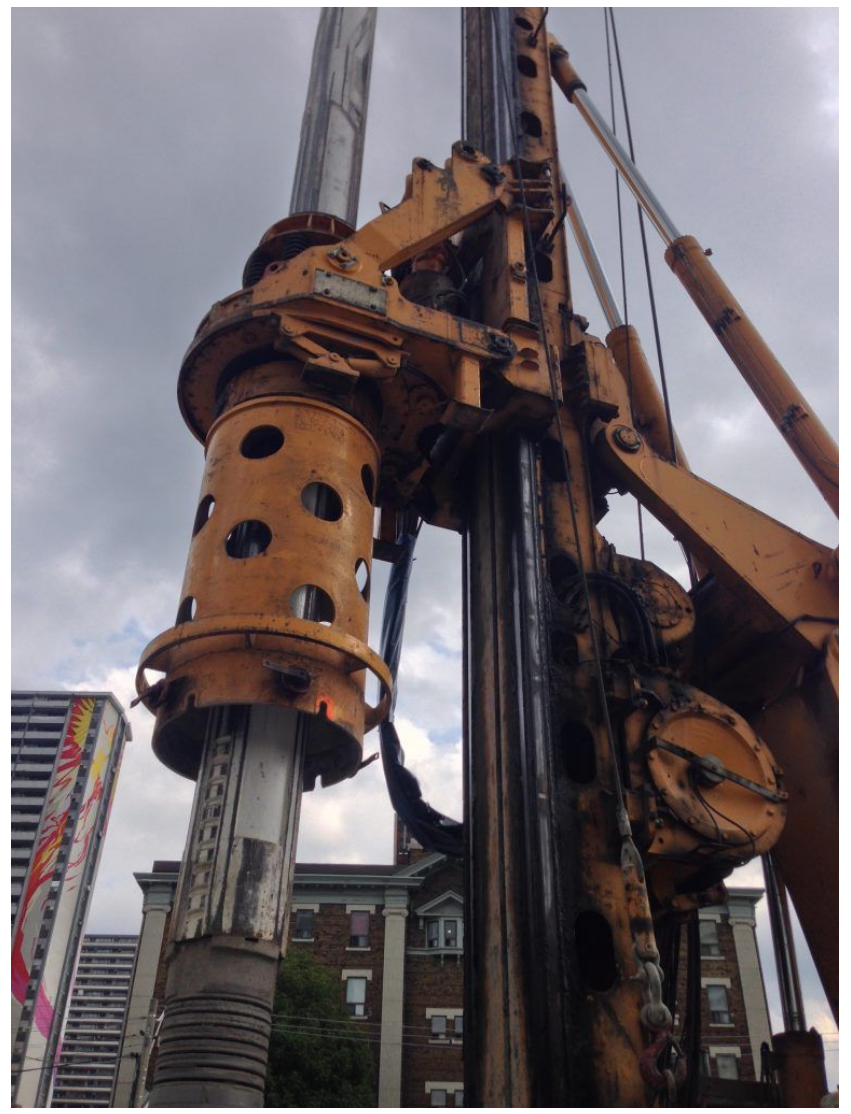

Fig 11 - Photograph featuring massive drill in operation in a building site. The drill is digging and boring down into ground to make way for the construction of a high-rise condominium. The photo is angled up to show the immensity of the equipment. In the background, the high-rise tower at 200 Wellesley is visible. Analytically, the combined sounds and pair of photos communicate that it is disruptive to be confronted with living in a perpetual construction zone.

4))

Link to Soundtrack 2: “Bleecker's Boundless Blasting and Brain Numbing Blaring”"

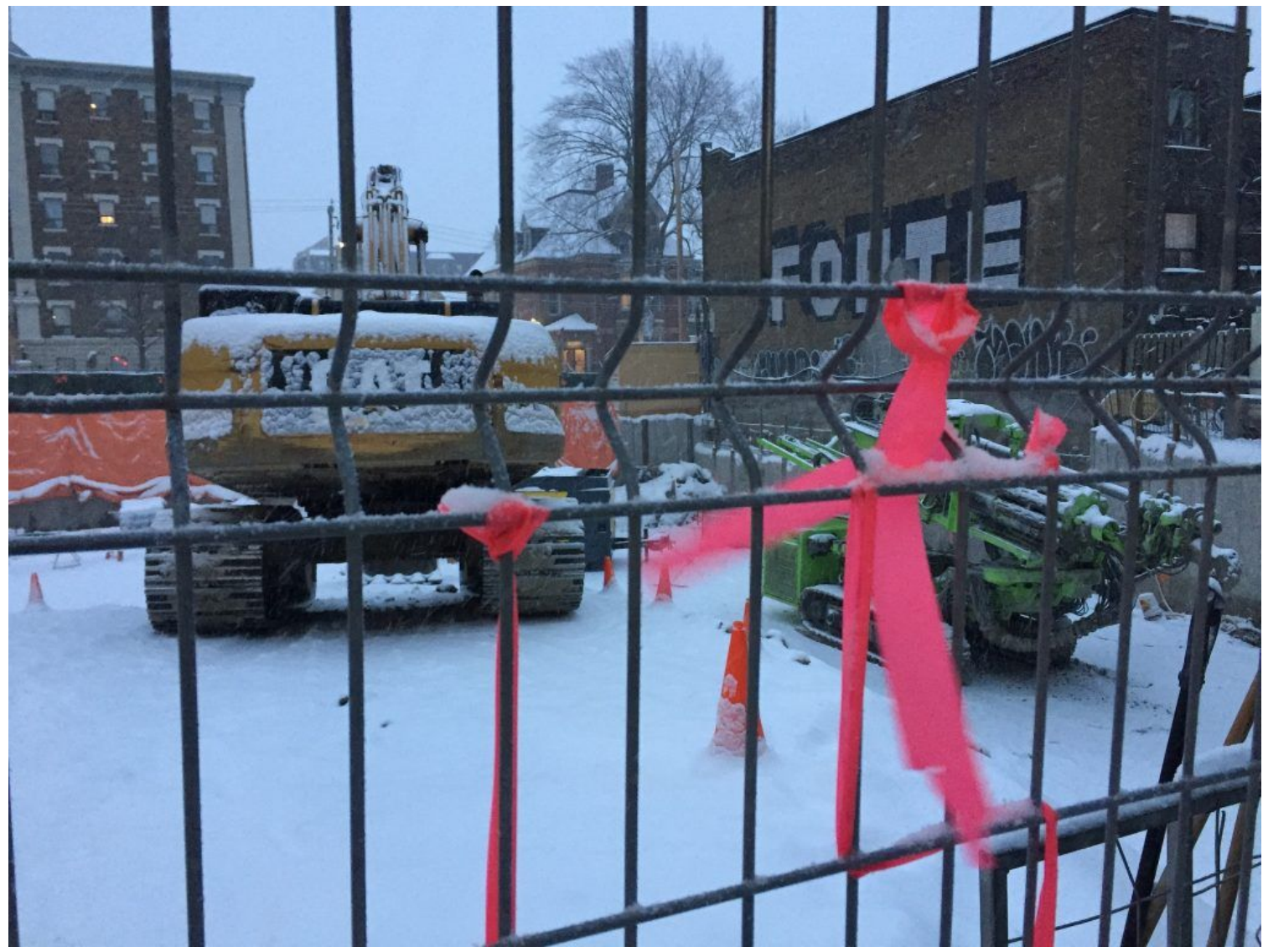

Fig 12 - Photograph taken in winter showing the same building site as photograph 11. The image is taken through a metal fence, behind which we see two massive pieces of industrial equipment. Other heavy metals and materials supporting construction are scattered around the gaping pit. Analytically, this photo communicates the idea that the neighbourhood has become an intense, active, year-round, building site. 
As I, Laura, reflect and write this article, I remember feeling responsible for showing and sharing St. James Town in humanizing and historically contextualized ways. This was, and still is, especially important for the three of us because our neighbourhood and its people have endured stigmatizing treatment of various sorts over the past thirty years. While incidents of crime have decreased, and as supply, demand and use of street drugs and associated practices, policies, habits, and policing have all shifted, so too have social realities and life in general in the neighbourhood. On the other hand, sociological and historically situated exploration of such changes and patterns are rarely, if ever, how our community makes the news or is represented in mainstream media (see Hume, 2017b).

The small group of us walked across the grass and toward the swimming pool near the high-rise at 280 Wellesley Street East. There, I related stories about the times my mother brought us to swim and enjoy ourselves on hot summer days. The pool is currently less frequented than in prior times. The condition of its infrastructure has steadily declined. As Maryam and I discussed this article with our mother, she was delighted in reminiscing at how vibrant a place the pool and its fenced-in compound had been, once-upon-a-time. It was definitely an energetic social hub for many residents. The pool also made possible relief from Toronto's raging summer humidity, offering vitalizing opportunities to learn and practice water sports. 


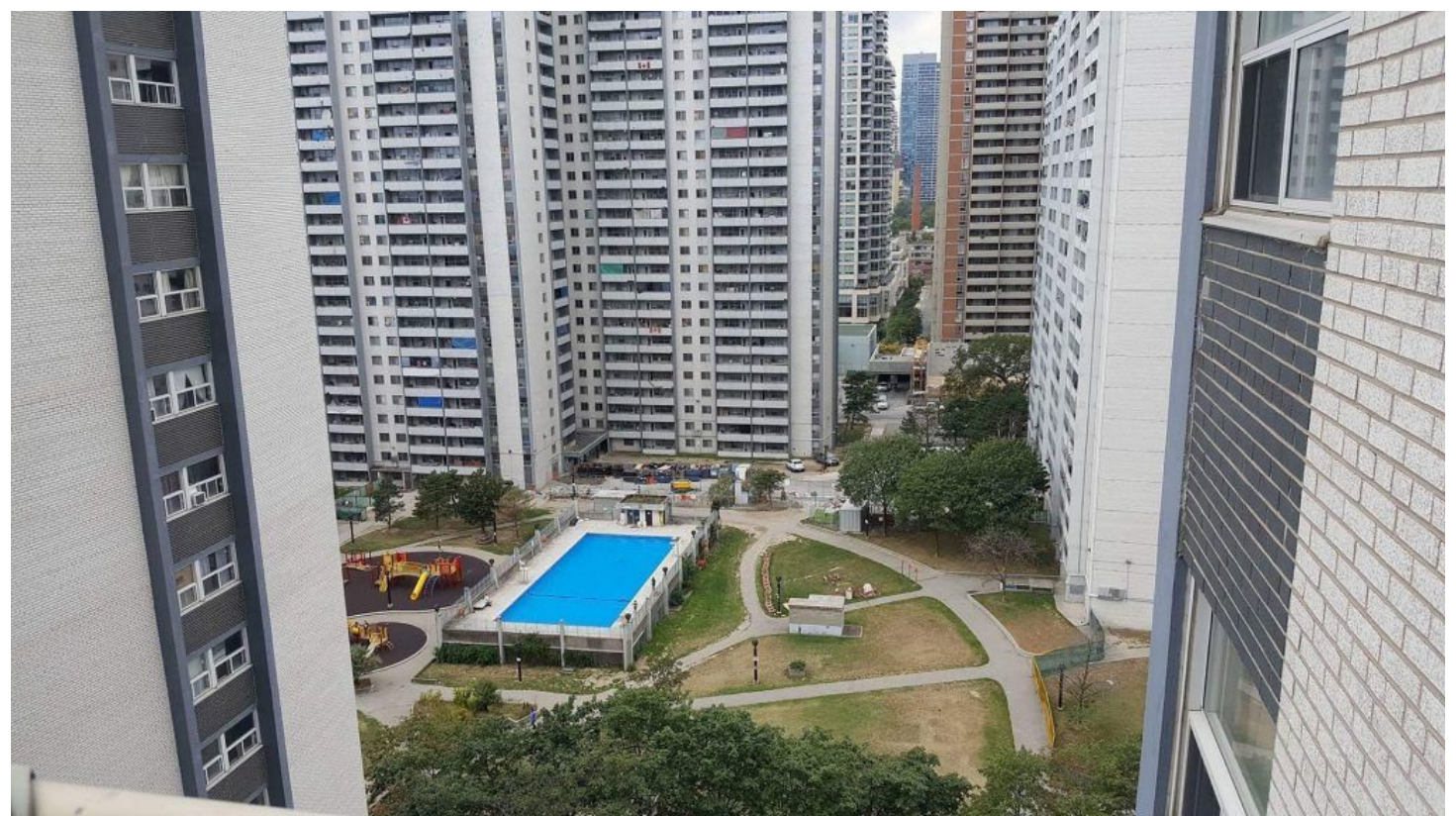

Fig 13 - Photograph taken from inside one of the high-rise apartment towers in St. James Town looking down. At the centre, a swimming pool, closed for the season, which is surrounded by about eight high-rise towers (idea of sentinels overlooking all that goes on below). Analytically, this image shows the area's extremely high-density and snug compact of its building footprints.

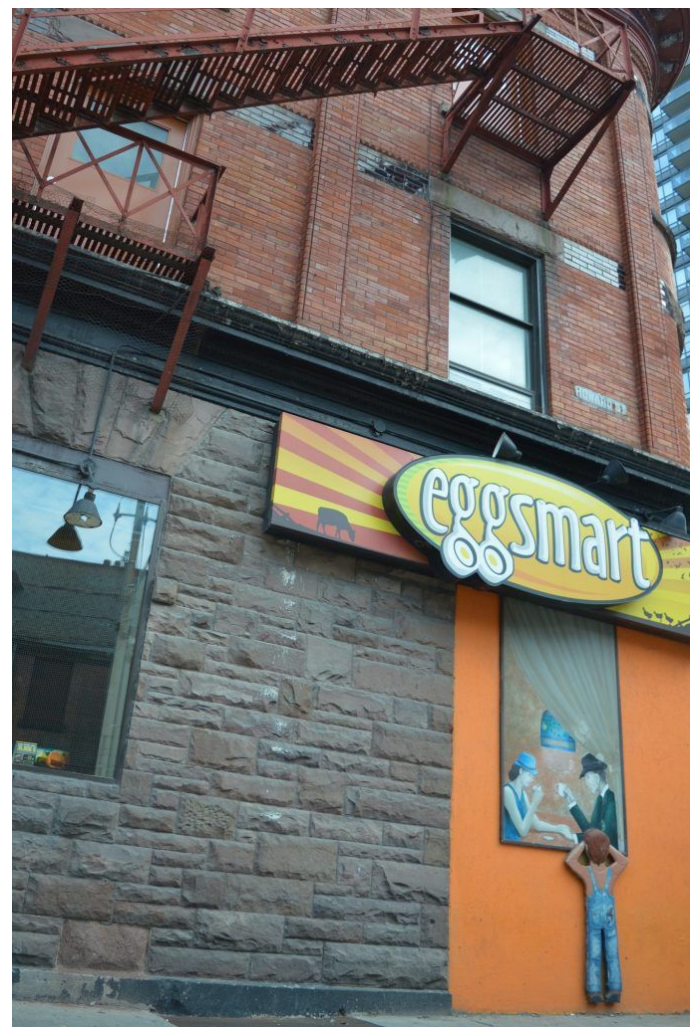

Fig 14 - Photograph taken outside of an orange coloured mural on the north-facing wall of a brick building on Howard Street, at the intersection with Sherbourne Street. The photograph is angled from the ground up, such that the building's ground and second floors, and glass condominium across the street, are visible.
After two hours, our site visit came to a close, and I walked my classmates to the Sherbourne subway station. I called their attention to the mural on a brick wall at the congested intersection of Sherbourne and Howard Streets. Featured is a young boy with his parents, their backs facing us. The artwork is on the north side of the 1902 Thomas Cruttenden Building (City of Toronto, 2010). The colour of the lower part of this building has changed over the last twenty years. Likewise, the corner store business, at this time a coffee shop 
franchise, has been repurposed. All the while, this mural has remained, largely unchanged. I noticed it for the first time when I was five years old and out walking with my father. When Maryam and I recently interpreted it, we imagined that the artist was commenting on social class stratification and consequences. This boy, tools in his pocket, is not of the leisure class, in contrast to the seated couple, who is out for a meal. Rather, he stands in for an apprentice labourer, asking whether the pair might have work for him. When we analyze St. James Town with an eye on social class arrangements, we see signs that materially well-off and less well-off people live and have lived here through time. The Cruttenden boy is a sentinel and sign of these patterns of co-habitation and mingled social relations. As my classmates and I discussed the mural, and I shared stories from life in this area and its human history, it comforted me. It represents stability and longevity, which is anchoring and soothing because this area is otherwise and seemingly always in flux as people come and go, and buildings vanish, are disrupted and restored, and are created anew.

The title of our article evokes and gestures toward former Canadian Prime Minister's April 2013 statement in which he identified how the federal government was preparing to respond to alleged acts of terrorism. "It is not a time to commit sociology," he stated with assurance, intimating to the public that overt signs of action were best responses. We disagree. Rather, we argue that committing sociology and engaging our sociological imagination is both an overt and valuable form of action. What is more, this is precisely the type of thoughtful social analysis that is needed, since it stands to produce contextualized understandings that can matter in people's lives. Naturally, we wonder 
what is in store for St. James Town as it continues to be transformed before our very eyes. What is certain, we will continue to work in solidarity with others in our home community, and we will use guidance from feminist scholarship and praxis, as we have done in this article.

In using our lived experiences and starting from the material conditions and circumstances of our lives and those of others near and dear to us, subjectivity has most assuredly grounded and enhanced our research (Taber, 2015). On one of our last face-to-face meeting to discuss our ideas for this article, our attention was, at one point, drawn to a long line-up of pigeons that were perched overhead and still others that were feverishly pecking at crumbs at the earth. It seemed to us that their nesting and balancing habits are disturbed by the construction, which is a point of common experience between them and us. These winged residents are skillful navigators and users of the urban space we share with them; returning as they do to specific resting places at the day's end. Mehdia and Maryam have been exploring and returning to St. James Town for their entire lives, and the three of us will continue to commit sociology as we observe the people, places, politics, and myriad transformations happening here. 


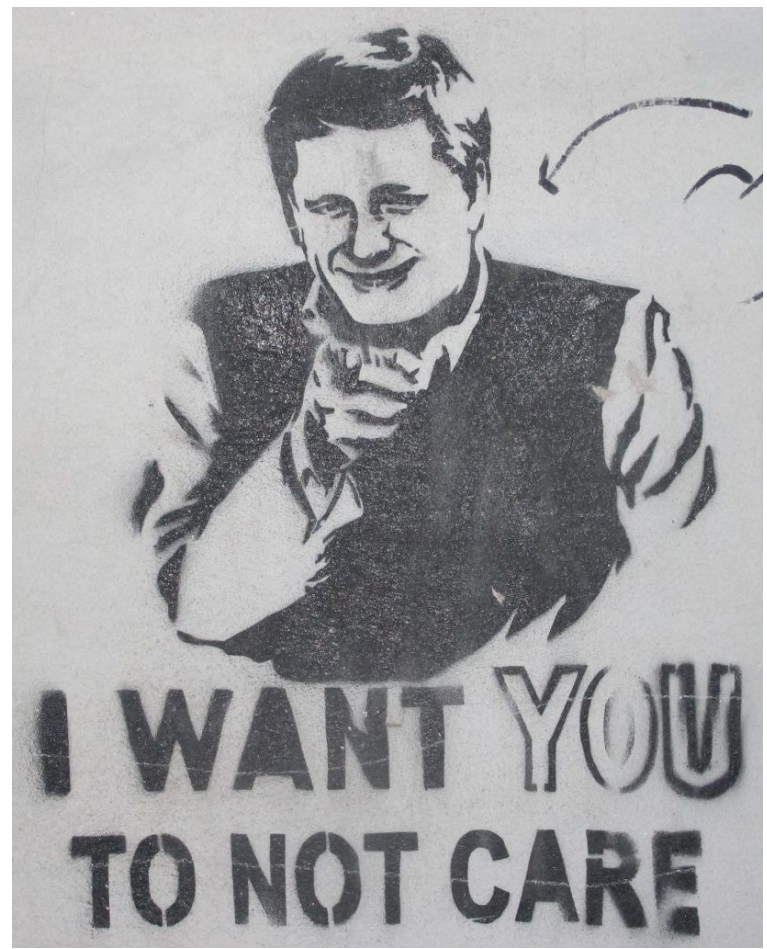

Fig 15 - Photograph taken outside featuring the torso and head of former Canadian Prime Minister, Stephen Harper. We see him smiling, right index finger pointed out at us. Below him, the statement "I want YOU not to care" appears in capital letters. Laura often walks by this graffiti, written in black and white spray paint, painted on the west-facing side of a brick home. It is located on the narrow, discrete Doctor O Lane (at the South end of Bleecker Street, across Carlton Street).

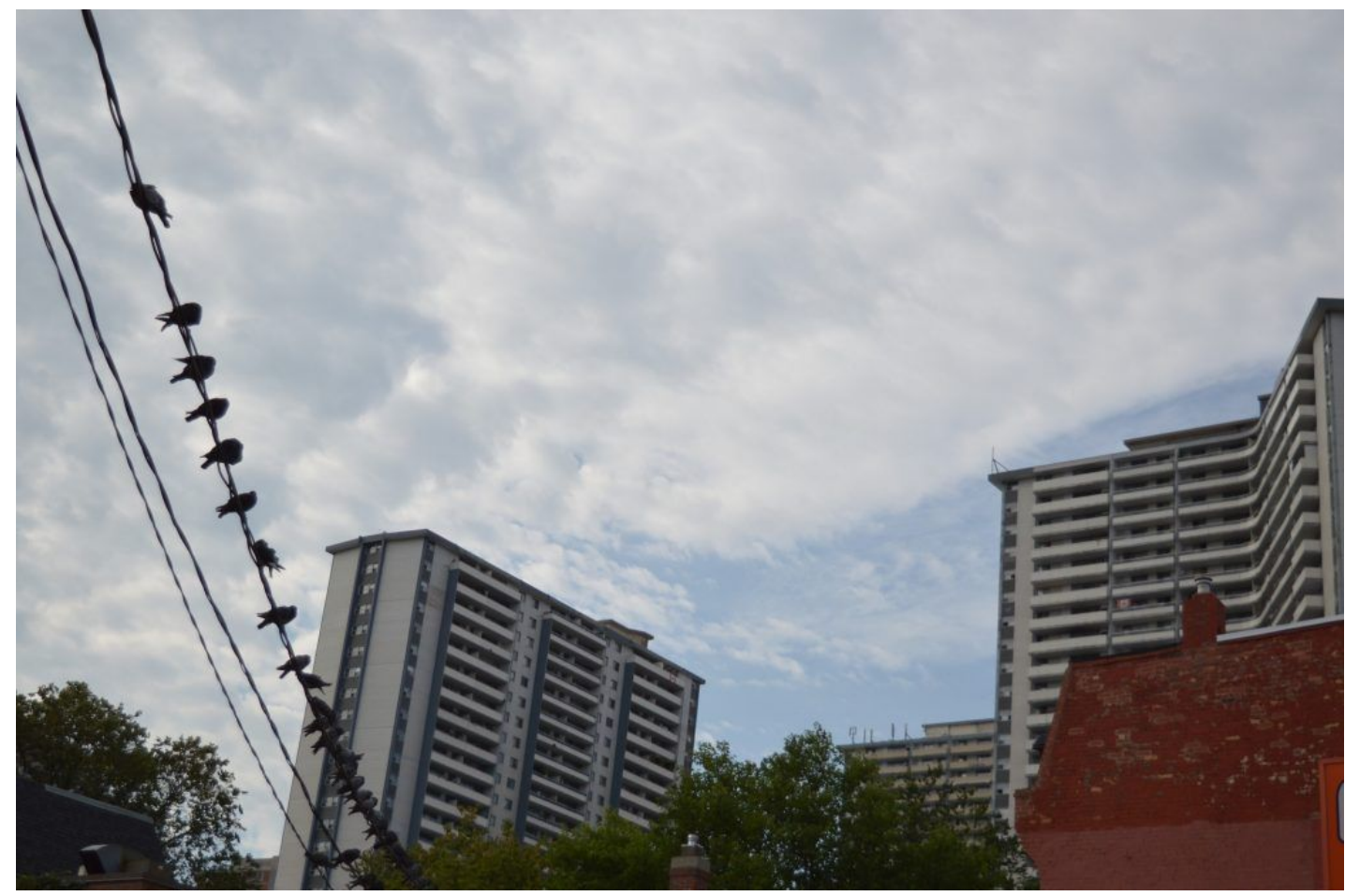

Fig 16 - Photograph taken outside featuring sparrows sitting on an overhead hydro wire. Angled from the ground-up, we see the mid-to upper-levels of three high-rise apartments in St. James Town. Blue, cloudy sky overhead.

D)) 


\section{References}

Barnes, S. (2011, Mar. 30). Canada's Densest Neighbourhood, St. Jamestown, to possibly get new Condos. Wellesley Institute. Retrieved from:

http://www.wellesleyinstitute.com/housing/st-james-town-residents-feel-powerles s-in-light-of-new-development-in-one-of-north-americas-densest-neighbourhoods /.

Bryant, T. (2016). Health Policy in Canada (2 $2^{\text {nd }}$ ed.). Toronto: Canadian Scholars' Press. City of Toronto (2010). Public Notice: Heritage Land. https://www.toronto.ca/involved/statutorynotices/archive2010/sept/hl_092910_14 .htm.

Contreras, R. (2015). Standpoint Purgatorio: Liminal Fear and Danger in Studying the 'Black and Brown' Tension in Los Angeles. In J. Auyero, P. Bourgois, \& N. Scheper-Hughes (Eds.), Violence at the Urban Margins (pp. 249-260). New York: Oxford University Press.

Eakin, J., \& Mykhalovskiy, E. (2005). 'Teaching Against the Grain: The Challenges of Teaching Qualitative Research in the Health Sciences. Forum: Qualitative Social Research 6 (2): 1-18.

El Magammar, R. (2017, Feb. 24). What Most Canadians Don’t Get About 'Bad Neighbourhoods' Like Mine. CBC News. Retrieved from: http://www.cbc.ca/2017/what-most-canadians-don-t-get-about-bad-neighbourhoo ds-like-mine-1.3992488.

Finn, P. (2015). Critical Condition: Replacing Critical Thinking with Creativity. Waterloo: Wilfred Laurier Press. 
Hume, C. (2017a, Sept. 12). City Must 'Talk the Talk' to Make Prudent Planning Decisions: Hume. The Toronto Star. Retrieved from: https://www.thestar.com/news/gta/2017/09/12/city-must-talk-the-talk-to-make-pr udent-planning-decisions-hume.html.

Hume, C. (2017b, May 16). How to Avoid the Next St. James Town: Hume. The Toronto Star. Retrieved from: https://www.thestar.com/news/gta/2017/05/16/how-to-avoid-the-next-st-james-to wn-hume.html.

Jungnickel, K., \& Hjorth, L. (2014). Methodological Entanglements in the Field: Methods, Transitions, and Transmissions. Visual Studies 29(2): 138-147.

Klinenberg, E. (1999). Denaturalizing Disaster: A Social Autopsy of the 1995 Chicago Heat Wave. Theory and Society 28(2): 239-295.

Lock, M., \& Nguyen, V-K. (2010). An Anthropology of Biomedicine. Hoboken: Wiley-Blackwell.

Mills, C. (1959, 2000). The Sociological Imagination. Oxford: Oxford University Press. Mountz, A. (2016). Women on the Edge: Workplace Stress at Universities in North America. Canadian Geographer 60(2): 205-218.

Mukhopadhyay, B. (2016). A Labour of Liberation. Regina: Changing Suns Press. Mykhalovskiy, E., \& Cain, R. (2008). Critical Work: Invigorating Critical Social Science and Humanities Research on HIVIAIDS in Ontario. Toronto: Ontario HIV Treatment Network.

Raphael, D. (2016). Social Determinants of Health: Canadian Perspectives ( ${ }^{\text {rd }}$ ed.). Toronto: Canadian Scholars' Press. 
Smith, D. (2006). Institutional Ethnography as Practice. Oxford: Rowman \& Littlefield.

Spencer, S., \& Cox, A. (2017). Into the Divide: Community Identities and the Visualisation of Place. Visual Studies 32(2): 97-110.

Taber, N. (2012). Beginning with the Self to Critique the Social: Critical Researchers as Whole Beings. In L. Naidoo (Ed.), An Ethnography of Global Landscapes and Corridors (pp. 73-88). Rijeka: InTech Publisher.

Toronto City Mission (2017). St. James Town. Retrieved from: http://www.torontocitymission.com/st-james-town/. 